\title{
Normas para la protección al salir de casa ante la pandemia COVID-19
}

\author{
Roberto Guillermo Calva y Rodríguez, ${ }^{\ddagger}, *$ Alicia Robledo-Galván, ${ }^{\ddagger}$ Alfredo Vigueras-Rendón, ${ }^{\ddagger}$ \\ Guillermo Yanowsky-Reyes, ${ }^{\ddagger}$ Francisco Paredes-Fernández, ${ }^{\ddagger}$ Manuel Gil-Vargas ${ }^{\ddagger}$ \\ ‡ Mesa Directiva de la Academia Mexicana de Pediatría, 2019-2021.
}

La Academia Mexicana de Pediatría, a través de la mesa directiva y el Departamento de Pediatría Social y Preventiva, presenta a la sociedad sus recomendaciones para la protección personal al salir y regresar a casa ante la pandemia de COVID-19, en particular cuando se requiera comprar alimentos:

\section{Normas para salir de casa}

- Una sola persona de buena salud deberá salir por alimentos.

- Procura tener una lista de artículos indispensable a la mano.

- Compra sólo lo indispensable, para una o dos semanas.

- Acude a tus compras lo más temprano posible.

- Siempre lleva un cubrebocas plisado.

- No toques el cubrebocas con tus manos.

- Lávate las manos antes de salir.

- Podrás emplear protección facial (careta), eso te protegerá mejor.

- Lleva bolsas de tela para guardar los alimentos.

- No saludes de mano.

- Si acudes en auto, desinfecta todas las superficies que se tocaron, con gel hidroalcohólico o con solución de cloro al $1 \%$.

\footnotetext{
* Correspondencia: RGCR, dr.robertocalvarodriguez@gmail.com Conflicto de intereses: Los autores declaran que no tienen. Citar como: Calva y Rodríguez RG, Robledo-Galván A, Vigueras-Rendón A, Yanowsky-Reyes G, Paredes-Fernández F, GilVargas M. Normas para la protección al salir de casa ante la pandemia COVID-19. Rev Mex Pediatr 2020; 87(3):119-120. doi: 10.35366/94844

[Guidelines for protection when leaving home during the COVID-19 pandemic]
}

- Si utilizas transporte público emplea cubrebocas, protector facial y un paño o guantes, o bien, usa tu mano no dominante.

- No bebas o comas durante el trayecto.

- No te toques el rostro, principalmente los ojos, nariz y boca.

- Desinféctate las manos con gel hidroalcohólico con frecuencia.

- Al estornudar o toser, taparte boca y nariz. Si utilizas pañuelos o toallas de papel, deséchalos en un lugar especial para ello y posteriormente lávate las manos.

- El lavado de manos con agua y jabón es lo más importante.

- No utilices joyas, relojes, pulseras, aretes, etcétera.

\section{Normas dentro de una tienda de alimentos}

- Recuerda que potencialmente todos los "objetos" que encuentres podrían estar contaminados.

- Si puedes emplear guantes desechables, como método complementario, es mejor.

- Utiliza toallas desechables con sanitizante para desinfectar el manillar del carrito de compras.

- No olvides llevar bolsas de tela para transportar tus artículos.

- De preferencia, deposita los artículos y/o alimentos directamente en las bolsas de tela.

- Trata de no tocar los "artículos" que no vayas a comprar.

- No toques la banda transportadora de la caja registradora.

- Guarda siempre una distancia prudente entre personas, es decir, al menos 1.5 metros. 
- No te toques el rostro, principalmente los ojos, nariz y boca.

- Compra productos que duren más tiempo, para asistir menos veces a la tienda.

- Evita el pago en efectivo.

- Se pueden lavar las monedas y los billetes con agua y jabón, para mayor seguridad.

- $\mathrm{Al}$ salir de la tienda, es necesario el lavado de manos con agua y jabón, en caso que no haya esta opción usar gel hidroalcohólico.

\section{Normas para regresar a casa}

- Prepara un espacio adecuado para vaciar el contenido de las bolsas para proceder a su desinfección.

- Las frutas y verduras lávalas con agua y jabón.

- Los alimentos que se encuentren empaquetados deben limpiarse con agua y jabón.

- Los alimentos o bebidas en frascos o botellas también se lavan con agua y jabón.

- Cuando sea posible, desecha el empaque de plástico o cartón y coloca el alimento en un contenedor.

- Lávate las manos al llegar a casa, antes y después de lavar los alimentos.

- Lava con agua y jabón las bolsas de tela con las que transportaste los alimentos.

- No te toques el rostro, principalmente los ojos, nariz y boca mientras realizas los procedimientos anteriores.
- Recuerda, antes de entrar a casa deja los zapatos en un lugar especial.

\section{Normas para utilizar el transporte público}

- Siempre lleva puesto un cubrebocas plisado y guantes.

- No toques el cubrebocas con tus manos.

- Lávate las manos después de tomar el transporte público.

- Emplea protección facial, eso te protegerá mejor, con careta y/o lentes.

- Mantén la distancia adecuada entre los usuarios.

- Utiliza asientos alternos y designados para el pasaje; en lo posible, no sentarse junto a otra persona.

- Recuérdale al chofer no subir personas de más, sólo las designadas a la unidad, con distancia adecuada.

- No aglomerarse en las marquesinas para tomar el transporte.

- Si estornudas utiliza la parte interna de tu codo.

- Si tienes que agarrarte del barandal o pasamanos puedes utilizar tu mano no dominante.

- No te toques el rostro, principalmente los ojos, nariz y boca.

- Desinféctate las manos con gel hidroalcohólico con frecuencia.

- El lavado de manos con agua y jabón es lo más importante.

- No utilices joyas, relojes, pulseras, aretes, etcétera.

- No bebas o comas durante el trayecto.

- No saludes de mano. 